\title{
Metallo-ß3-Lactamase Producing Pseudomonas species in a Tertiary Care Hospital of Dhaka City
}

\author{
Tanzinah Nasrin ${ }^{1}$, Md. Shariful Alam Jilani ${ }^{1}$, Lovely Barai ${ }^{2}$, J. Ashraful Haq ${ }^{1}$ \\ ${ }^{1}$ Department of Microbiology, Ibrahim Medical College and BIRDEM Hospital, ${ }^{2}$ Department of Microbiology, BIRDEM
}

\begin{abstract}
Among the various beta-lactam antibiotics, carbapenems are the most potent and have been reserved for use in treating infections caused by multi-drug resistant (MDR) Gram negative bacilli, especially Pseudomonas. They are effective even against Extended Spectrum beta-lactamase (ESBL) and Amp C b-lactamase producing bacteria. The clinical utility of carbapenems is under threat with the emergence of carbapenem resistant bacteria due to production of carbapenem hydrolyzing metallo-beta-lactamase (MBL) which confers high-level resistance to all b-lactam antibiotics except aztreonam. The prevalence of MBLs have been studied in many countries but not been reported in Bangladesh. The purpose of the study to determine the presence of MBLs producing Pseudomonas in clinical samples from a tertiary care hospital. MBLs producing Pseudomonas in various clinical samples of an urban hospital of Dhaka city was investigated over a 6-month period (January 2009-June 2009). EDTA-IMP agar dilution minimum inhibitory concentration (MIC) reduction method was employed to detect MBL producing Pseudomonas sp. Out of 44 Pseudomonas isolates 08 (18.2\%) were sensitive and $23(52.3 \%)$ were resistant to imipenem while $13(29.5 \%)$ were intermediate resistant $(\mathrm{MIC}=8 \mu \mathrm{g} / \mathrm{ml})$ to imipenem. All Pseudomonas showing intermediate resistance to imipenem were found sensitive by disc diffusion method. MBL phenotype was detected in 43\%(10 out of 23) imipenem resistant Pseudomonas spp. while the rate was $61 \%(08$ out of 13) is intermediate resistant strains by EDTA-IMP agar dilution MIC method. The results of the study indicated high prevalence of MBL producing Pseudomonas spp. in our hospital environment. Early detection of these MBL producing Pseudomonas is necessary to institute appropriate treatment and effective infection control measures.
\end{abstract}

Key words: Metallo-3-lactamase, Pseudomonas species, Gram negative bacilli.

\section{Introduction}

Development of antibiotic resistance is a major concern in the management of bacterial infections. Carbapenems are often used as antibiotics of last resort for treating infections due to multi-drug resistant Gram-negative bacilli. They are stable against extended spectrum beta-lactamase (ESBL) and AmC beta-lactamase. However, this scenario is changing with the emergence of metallo- -lactamase (MBL) producing strains. The MBLs can efficiently hydrolyze all beta-lactam

\section{Correspondence:}

Md. Shariful Alam Jilani

Department of Microbiology

Ibrahim Medical College \& BIRDEM Hospital

122 Kazi Nazrul Islam Avenue, Shabagh, Dhaka 1000.

Email: jilanimsa@gmail.com antibiotics except aztreonam. ${ }^{1}$ MBL producing Gramnegative bacilli, specially Pseudomonas sp, have been increasingly reported in Asia, Europe, Latin American and the United States. ${ }^{2-5}$ Therefore, detection of MBL-producing Gram negative bacilli is crucial for the optimal treatment of patients and to control the spread of resistance.

At present no data is available on MBL producing organisms in Bangladesh. Therefore, the present study was undertaken to detect the prevalence of MBL-producing Pseudomonas in a tertiary care hospital of Dhaka city.

\section{Methods}

Study population and specimens

All samples were collected from hospitalized patients of Bangladesh Institute of Research and Rehabilitation in Diabetes, Endocrine and Metabolic Disorder (BIRDEM). The 
study was carried out during December, 2008 to June, 2009. The specimens included were pus, blood, urine and tracheal aspirates. Production of MBL was tested in Pseudomonas sp only.

\section{Microbiological methods}

All samples were routinely cultured on MacConkey and blood agar plates. Blood culture was done by lytic centrifugation method. ${ }^{6}$ All suspected colonies of Pseudomonas were identified by Gram staining, colony characteristics, positive oxidase test, motility and standard biochemical reactions. ${ }^{7}$

\section{Antibiotic susceptibility testing}

Antimicrobial susceptibility testing of the isolated organisms was done by a disk diffusion method using the Kirby-Bauer technique ${ }^{8}$ and as per the recommendations of the NCCLS. ${ }^{9}$ All disks were obtained from Oxoid Ltd., Basingstoke, Hampshire, UK. Antibiotic potency of the disks was standardized against the reference strain, Pseudomonas aeuruginosa ATCC 25853.

\section{Detection of MBL production}

Production of MBL by Pseudomonas spp. is determined by EDTA-imipenem (EDTA-IMP) agar dilution MIC reduction method. ${ }^{10}$ The EDTA-IMP agar dilution MIC reduction test was a modification of EPI microdilution MIC test as described by Migliavacca et al. ${ }^{11}$ The test was used as gold standard for detection of MBLs production in this study.

Briefly, MIC of imipenem of isolated Pseudomonas sp was determined with or without EDTA of defined concentration. First, MIC of imipenem of test organisms was performed by agar dilution method with imipenem concentration between $0.125-1024 \mu \mathrm{g} / \mathrm{ml}$. Then, again MIC of imipenem of test organism was determined in presence of combination of imipenem and 0.4mM EDTA. Muller-Hinton agar plates were prepared with suspensions of $0.125 \mu \mathrm{g} / \mathrm{ml}, 0.25 \mu \mathrm{g} / \mathrm{ml}$, $0.5 \mu \mathrm{g} / \mathrm{ml}, 1 \mu \mathrm{g} / \mathrm{ml}, 2 \mu \mathrm{g} / \mathrm{ml}, 8 \mu \mathrm{g} / \mathrm{ml}, 16 \mu \mathrm{g} / \mathrm{ml}, 32 \mu \mathrm{g} / \mathrm{ml}$, $64 \mu \mathrm{g} / \mathrm{ml}, 128 \mu \mathrm{g} / \mathrm{ml}, 256 \mu \mathrm{g} / \mathrm{ml}, 512 \mu \mathrm{g} / \mathrm{ml}, 1024 \mu \mathrm{g} / \mathrm{ml}$ imipenem plus $0.4 \mathrm{mM}$ EDTA. A fixed inoculum of $10^{4} \mathrm{cfu}$ of the test strains was inoculated on these plates. The reading was taken after 24 hours of incubation. The highest dilution that inhibited the growth of the organism was taken as MIC of the test organism. An organism was considered MBL positive if the MIC of imipenem was reduced by fourfold or more in presence of EDTA compared to MIC of imipenem alone.

\section{Result}

A total of 44 Pseudomonas were isolated from various clinical samples of which $08(18.2 \%)$ were sensitive, while 13 $(29.5 \%)$ and $23(52.3 \%)$ were intermediate resistant (MIC $=8$ $\mu \mathrm{g} / \mathrm{ml}$ ) and resistant (MIC $16 \mu \mathrm{g} / \mathrm{ml}$ ) to imipenem respectively (Table-1). All 44 Pseudomonas isolates were tested for production of MBL by EDTA-IMP agar dilution MIC method.

Table 1: Rate of isolation of MBL-producing Pseudomonas sp $(\mathrm{n}=44)$ by IMP (imipenem) agar dilution MIC method.

\begin{tabular}{lllll}
\hline MBLs & $\begin{array}{l}\text { No. of total tested } \\
\text { Pseudomonas } \\
44\end{array}$ & $\begin{array}{l}\text { Imipenem MICs } \\
\text { resistant } \\
\text { MIC }=16 \mu \mathrm{g} / \mathrm{ml}\end{array}$ & $\begin{array}{l}\text { Imipenem MICs } \\
\text { intermediate resistant } \\
\text { MIC }=8 \mu \mathrm{g} / \mathrm{ml}\end{array}$ & $\begin{array}{l}\text { Imipenem MICs } \\
\text { sensitive } \\
\text { MIC= } 4 \mu \mathrm{g} / \mathrm{ml}\end{array}$ \\
\hline Positive & 18 & 10 & 8 & 0 \\
Negative & 26 & 13 & 5 & 8 \\
\hline
\end{tabular}

MBL detected in 43\% (10 out of 23) imipenem resistant spp. while $61 \%$ ( 08 out of 13$)$ in intermediate resistant strains as they showed $\geq$ fourfold reduction of imipenem MIC in presence of chelating agents EDTA (Table: 2).

Table 2: Rate of isolation of MBL-producing Pseudomonas sp by IMP-EDTA agar dilution MIC method.

\begin{tabular}{lll}
\hline MBLs & $\begin{array}{l}\text { Imipenem MICs } \\
\text { resistant MIC }=16 \mu \mathrm{g} / \mathrm{ml} \\
(\text { Total=23) }\end{array}$ & $\begin{array}{l}\text { Imipenem MICs intermediate } \\
\text { resistant MIC }=8 \mu \mathrm{g} / \mathrm{ml} \\
(\text { Total=13) }\end{array}$ \\
\hline Positive & $10(43 \%)$ & $8(61 \%)$ \\
Negative & 13 & 5 \\
\hline
\end{tabular}

\section{Discussion}

In the present study, about $43 \%$ of Pseudomonas isolated from various clinical samples were MBL producers. But it is interesting to note that $61 \%$ of MBL producing Pseudomonas were detected among those which showed intermediate resistance to imipenem by MIC. Therefore it appears that these strains could be low level producers of MBL. The clinical outcome of patients infected with such imipenem sensitive, as shown by routine disc diffusion test, but low level MBL producing organisms remains unknown. Similar observation was made in other countries where Klebsiella pneumoniae and Escherichia coli isolated from clinical samples were found carbapenem sensitive but positive for MBL gene. ${ }^{12-15}$

The high rate of MBL positive Pseudomonas in our study was probably due to the fact that majority of our strains were isolated from Intensive Care Units (ICU) samples. In Japan, the rate of resistance to carbapenems increased from $19.3 \%$ in 1998 to $38 \%$ in $2002 . .^{5}$ A study in a tertiary-care teaching hospital in southern Brazil reported high rates (56.7-58.3\%) of imipenem resistance among $P$. aeruginosa.${ }^{15}$ In Italy, about $20 \%$ of all $P$. aeruginosa and $70 \%$ of carbapenem resistant strains contained MBLs. ${ }^{10}$ We are unable to determine the trends of MBL producing Pseudomonas in clinical specimens as our study was the first to detect MBLs producing organisms from clinical specimens in Bangladesh. 
The results of the study indicated a high prevalence of MBL producing Pseudomonas in tertiary care hospital of Dhaka city.

\section{References}

1. Bush K, Jacoby GA, Medeiros AA. Infectious Diseases 2005; 1. Bush K, Jacoby GA, Medeiros AA. A functional classification scheme for -Lactamases and its correlation with molecular structure. Antimicrob. Agents Chemother. 1995; 39: 1211-33.

2. Chu YW, Shah MA, Houang ETS, Palepou MF, Lyon DJ, Woodford N and.Livermore DM. IMP-4, a novel metallo-betalactamase from nosocomial Acinetobacter spp. collected in Hong Kong between 1994 and 1998. Antimicrob. Agents Chemother. 2001; 45: 710-4.

3. Kurokawa, HT. Yagi T, Shibata N, Shibayama K and Arakawa Y. Worldwide proliferation of carbapenem-resistant gram-negative bacteria. Lancet 1999; 354-5.

4. Toleman, MA, Rolston K, Jones RN and Walsh TR. Characterization of bla ${ }_{\mathrm{VIM}-7}$ from Pseudomonas aeruginosa isolated in the United States: an evolutionary distinct metallobeta-lactamase gene. Antimicrob. Agents Chemother. 2004; 48: 329-32.

5. Fritsche TR., Sader HS, Toleman MA., Walsh TR. and Jones RN. Emerging Metallo-beta-Lactamase-Mediated Resistances: A Summary Report from the Worldwide SENTRY Antimicrobial Surveillance Program. Clinical Infectious Diseases 2005; 41: 276-8.

6. O'Hara CM, Melvin PW, Miller JM. Manual and Automated systems for detection and identification of microorganisms In: Patrick RM, Ellen JB, James HJ, Miccael AP, Robert HY (Editors) Manual of Clinical Microbiology, $8^{\text {th }}$ Edition. Washington D.C. ASM Press, 2003; 1: 185-207.

7. Dianna LK, Peter HG. Pseudomonas. In: Patrick RM, Ellen JB, James HJ, Miccael AP, Robert HY (Editors) Manual of Clinical Microbiology, $8^{\text {th }}$ Edition. ASM Press, Washington D.C. 2003; 1: 719-728.

8. Bauer AW, Kirby WMM, Sherris JC, Turek M. Antibiotic sensitivity testing by a standardized single disk method. Am. J. Clin. Path. 1966; 45: 493-6.

9. National Committee for Clinical Laboratory Standards. Performance Standards for Antimicrobial Susceptibility Testing: Eleventh informational Supplement. NCCLS document M100S11 NCCLS. Wayne, Pennsylvania, USA. 2001.

10. Lagatolla C, Tonin EA, Monti-Bragadin C, Dolzani L, Gombac F, Bearzi C, Edalucci E, Gionechetti F and Rossolini GM. Endemic carbapenem resistant Pseudomonas aeruginosa with acquired metallo-beta-lactamase determinants in European hospital. Emerg. Infect. Dis. 2004; 10: 535-8.

11. Migliavacca R., Docquier JD, Mugnaioli C, Amicosante G,
Daturi R, Lee KW, Rossolini GM and Pagani L. Simple microdilution test for detection of metallo-beta-lactamase production in Pseudomonas aeruginosa. J. of Clin. Microbiol. 2002; 40(11): 4388-90.

12. Arakawa Y, Shibata N, Shibayama K, Kurokawa H, Yagi T, Fujiwara $\mathrm{H}$ and Goto $\mathrm{M}$. Convenient test for screening metallobeta-lactamase producing gram-negative bacteria by using thiol compounds, J. Clin. Microbiol. 2000; 38(1): 40-3.

13. Franklin C, Liolios L, and Peleg AY. Phenotypic detection of carbapenem-susceptible metallo-lactamase producing Gramnegative bacilli in the clinical laboratory. Journal of Clinical Microbiology 2006; 44: 3139-44.

14. Scoulica, EV, Neonakis IK, Gikas AI and Tselentis YJ. Spread of blaVIM-1-producing E. coli in a university hospital in Greece. Genetic analysis of the integron carrying the blaVIM-1 metallobeta-lactamase gene. Diagnostic Microbiol. Infect. Dis. 2004; 48: $167-72$.

15. Yan JJ, Ko WC, Tsai SH, Wu HM and Wu JJ. Outbreak of infection with multidrug-resistant Klebsiella pneumoniae carrying blaIMP-8 in a university medical center in Taiwan. $J$. Clin. Microbiol. 2001; 39: 4433-9.

16. Zavascki, AP, Barth AL, Gaspareto PB, et al. Risk factors for nosocomial infections due to Pseudomonas aeruginosa producing metallo-beta-lactamase in two tertiary-care teaching hospitals. J. Antimicrob. Chemother. 2006; 58: 882-5. 